\title{
Dual inhibition of MET and SRC kinase activity as a combined targeting strategy for colon cancer
}

\author{
NA SONG ${ }^{1}$, XIUJUAN QU ${ }^{1}$, SHIZHOU LIU ${ }^{2}$, SIMENG ZHANG ${ }^{1}$, JING LIU $^{1}$, \\ JINGLEI QU ${ }^{1}$, HUACHUAN ZHENG ${ }^{3}$, YUNPENG LIU ${ }^{1 *}$ and XIAOFANG CHE ${ }^{1 *}$ \\ ${ }^{1}$ Department of Medical Oncology, The First Hospital of China Medical University, Shenyang, \\ Liaoning 110001; ${ }^{2}$ Institute of Translational Medicine, Zhejiang University, Hangzhou, Zhejiang $310029 ;{ }^{3}$ Department of \\ Experimental Oncology, Shengjing Hospital of China Medical University, Shenyang, Liaoning 110001, P.R. China
}

Received June 24, 2016; Accepted April 10, 2017

DOI: $10.3892 / e t m .2017 .4692$

\begin{abstract}
Hepatocyte growth factor (HGF)/MET signaling is implicated in the development of colorectal cancer (CRC) and possesses therapeutic value for various types of cancer. However, inhibition of MET alone has been demonstrated to have limited efficacy. The present study examined the combined inhibition of MET and SRC kinase activity in colon cancer cells. Furthermore, the role of the HGF/MET pathway in ligand-dependent and -independent activation was demonstrated. The single inhibition of MET by knockdown small interfering RNA or inhibitor indicated a limited anti-viability effects without inhibiting the basal phosphorylation levels of SRC, protein kinase B (AKT) or extracellular signal-regulated kinase (ERK). In view of the strong association between MET and SRC identified by direct regulation, growth factor-induced MET activation was suppressed by pretreatment with the SRC inhibitor, dasatinib, and downstream phosphorylation of AKT and ERK partially decreased, which suggested that SRC activation was essential for ligand-dependent and -independent activation of MET. Considering that both the activation of MET and SRC was required in ligand-dependent and -independent MET activation, the antitumor effect of concurrent inhibition of MET and SRC was examined, and it was demonstrated that combination treatment exerted increased viability inhibition and apoptosis enhancement in mutant and wild type RAS colon cancer cells. Therefore, combinational inhibition of MET and SRC may be a promising strategy for the treatment of CRC.
\end{abstract}

Correspondence to: Professor Yunpeng Liu or Professor Xiaofang Che, Department of Medical Oncology, The First Hospital of China Medical University, 155 North Nanjing Street, Shenyang, Liaoning 110001, P.R. China

E-mail: cmuliuyunpeng@hotmail.com

E-mail: xf_che@hotmail.com

*Contributed equally

Key words: MET, SRC, colon cancer, targeted therapy

\section{Introduction}

The current management of metastatic colorectal cancer (CRC) involves chemotherapy and monoclonal antibodies targeting vascular endothelial growth factor (VEGF; bevacizumab) or epidermal growth factor receptor (EGFR; cetuximab and panitumumab). However, when available standard therapies are unsuccessful, patients may require additional treatment. The overall survival rate of patients with metastatic CRC has increased in recent years (1), and more patients for whom the standard therapies have failed, with a promising performance status may be candidates for further therapy (2).

Previous efforts to develop small-molecule kinase inhibitors have been unsuccessful in CRC. Until 2012, regorafenib was demonstrated to be the first small-molecule inhibitor with a survival benefit in patients with metastatic CRC in which standard therapy had failed in a randomized phase III study (3). Furthermore, regorafenib is an oral multi-kinase inhibitor that targets several protein kinases involved in tumor angiogenesis, such as VEGF receptor 1-3 (VEGFR1-3) and tyrosine kinase with immunoglobulin and epidermal growth factor homology domain 2 (TIE2), oncogenesis, such as KIT, RET, RAF1 and BRAF, and the tumor microenvironment, including platelet-derived growth factor receptor and fibroblast growth factor receptor (4). The successful application of regorafenib suggested that small-molecule kinase inhibitors may be available, effective and safe for treatment of metastatic CRC. In addition, the most effective outcome of regorafenib that may clinically benefit patients may lie in combined targeting (3-5). Therefore, it is necessary to develop additional combined targets for creating treatment options for CRC.

Multiple signaling pathways have been implicated in the development and progression of CRC, involving transmembrane receptor tyrosine kinases (RKTs), such as EGFR, VEGFR, insulin-like growth factor-1 receptor (IGF-1R) and MET, and downstream signaling cascades $(2,6)$. Furthermore, hepatocyte growth factor (HGF) and its receptor, MET, are crucial in uncontrolled cell survival, growth, angiogenesis and metastasis (7). Additionally, functional crosstalk between MET and other TKRs has emerged as a major mechanism for tumor progression and therapy resistance (8-10). The activated MET-driven phosphoinositide 3-kinase (PI3K) signaling 
pathway predicts poor survival in patients with CRC, which is independent of their KRAS mutational status (11). Furthermore, research has indicated that patients with MET amplification or protein expression were significantly associated with poorer survival $(12,13)$. In CRC, amplification of MET (on chromosome 7q31) may occur; however, the prevalence of MET amplification overall in CRC was as low as $1 \%$ (14). Notably, MET amplification may develop and drive resistance to anti-EGFR therapies in CRC, highlighting the requirement for MET inhibitors in patients who have exhibited resistance as a result of MET amplification (14). For these reasons, MET acts as one of the principal targets within multitargeted small molecule tyrosine kinase inhibitors.

Aberrant MET signaling sequentially activates various downstream signaling cascades, which is predominantly mediated by the extracellular signal-regulated kinase (ERK)-mitogen-activated protein kinase and PI3K-protein kinase B (AKT) pathways (7). In multiple downstream pathways, SRC family kinases (SFKs) are important central mediators that interact with multiple TKRs, representing a promising target in cancer therapy (15). For instance, activation of SRC has been demonstrated to confer resistance to targeted therapies, including anti-EGFR and anti-human epidermal growth receptor $2(16,17)$. Although SRC activity serves as a key downstream node, single-agent treatment of SRC inhibitor has been demonstrated to have limited clinical benefit, and combination regimens with targeted therapy have indicated more clinically relevant effects (18). Generally, bypass activation of MET is accompanied with downstream activation of SRC (19). Furthermore, the interaction of MET with SRC mediates resistance to targeted drugs (20-22). Although the association between MET and SRC has been demonstrated to cooperate intensely (20), few studies have focused on the effect of dual inhibition of MET and SRC in targeted therapy.

Previous research has demonstrated that cetuximab-induced MET and SRC activation was involved in the resistance to cetuximab in colon cancer cells (22). Furthermore, single addition of MET inhibitor, PHA-665752, or the multitargeted SFK inhibitor, dasatinib, exerted certain antitumor effects in colon cancer cells (22). Therefore, the present study further investigated the role of MET activation in the ligand-dependent and -independent $\mathrm{HGF} / \mathrm{MET}$ pathway, the interaction between MET and SRC and the mechanisms underlying the antitumor effect of MET and SRC inhibitors in colon cancer cells, providing a rationale for combinatorial inhibition of MET and SRC in therapy targeting colon cancer.

\section{Materials and methods}

Cell culture and reagents. Colon cancer cells, HT-29 and HCT-116, were obtained from the Type Culture Collection of the Chinese Academy of Sciences (Shanghai, China). The two cell lines were cultured at $37^{\circ} \mathrm{C}$ with $5 \% \mathrm{CO}_{2}$ in RPMI-1640 medium (Gibco; Thermo Fisher Scientific, Inc., Waltham, MA, USA) supplemented with $10 \%$ fetal bovine serum (FBS; Gibco; Thermo Fisher Scientific, Inc). HGF, epidermal growth factor (EGF) and IGF-1 were purchased from R\&D Systems, Inc. (Minneapolis, MN, USA). PHA-665752 was purchased from Sigma-Aldrich (Merck KGaA, Darmstadt, Germany). Dasatinib was purchased from Selleck Chemicals (Houston,
TX, USA). Antibodies against MET (cat. no. 3127; 1:1.000), phosphorylated (p)-MET (Tyr1234/1235; cat. no. 3077; 1:500), SRC (cat. no. 2110; 1:1,000), p-SRC (Y416; cat. no. 6943; 1:500), AKT (cat. no. 9272; 1:1,000), p-AKT (Ser473; cat. no. 9271; 1:1,000), EGFR (cat. no. 2646; 1:1,000), p-EGFR (Tyr1068; cat. no. 2234; 1:500), IGF-1R (cat. no. 3027; 1:1,000), p-IGF-1R (Tyr1131; cat. no. 3021; 1:500) and poly (ADP-ribose) polymerase (PARP; cat. no. 9542; 1:1,000) were obtained from Cell Signaling Technology, Inc., (Danvers, MA, USA). Anti- $\beta$-actin (cat. no. sc-1616; 1:1,000), anti-ERK (cat. no. sc-292838; 1:1,000), p-ERK1/ERK2 (Thr202/Tyr204; cat. no. sc-16982; 1:1,000), horseradish peroxidase-conjugated secondary goat anti-rabbit (cat. no. sc-2385; 1:2,000) and goat anti-mouse (cat. no. sc-2375; 1:2,000) antibodies were purchased from Santa Cruz Biotechnology, Inc., (Dallas, TX, USA).

Cell viability assay. Cell viability was measured using an MTT assay. HT-29 and HCT-116 cells were seeded in triplicate at 6,000 cells/well in 96-well plates and incubated at $37^{\circ} \mathrm{C}$ for $24 \mathrm{~h}$ in RPMI-1640 medium supplemented with 10\% FBS. Subsequently, cells were treated with the indicated doses of HGF $(5,25$ or $125 \mathrm{ng} / \mathrm{ml})$, PHA-665752 $(0.2,1.0$ or $5.0 \mu \mathrm{M})$, dasatinib $(0.1,0.5$ or $2.5 \mu \mathrm{M})$ or a combination $(0.1 \mu \mathrm{M}$ dasatinib and $0.2 \mu \mathrm{M}$ PHA) for $48 \mathrm{~h}$ at $37^{\circ} \mathrm{C}$. The same volume of dimethylsulfoxide (DMSO) was used as the negative control. Following this, $25 \mu \mathrm{l} \mathrm{MTT}$ solution $(5 \mathrm{mg} / \mathrm{ml})$ was added to each well for $4 \mathrm{~h}$ at $37^{\circ} \mathrm{C}$, cell culture supernatants were carefully removed and $200 \mu \mathrm{l}$ DMSO was added. Finally, the optical density was measured at a wavelength of $570 \mathrm{~nm}$ using a microplate reader (Model 550; Bio-Rad Laboratories, Inc., Hercules, CA, USA).

Western blot analysis. The cells were washed twice with phosphate-buffered saline (PBS), lysed in lysis buffer $(1 \%$ Triton X-100, $50 \mathrm{mM}$ Tris- $\mathrm{HCl} \mathrm{pH} 7.4,150 \mathrm{mM} \mathrm{NaCl}$, $10 \mathrm{mM}$ EDTA, $100 \mathrm{mM} \mathrm{NaF}, 1 \mathrm{mM} \mathrm{Na} \mathrm{VO}_{4}, 1 \mathrm{mM}$ PMSF, $2 \mu \mathrm{g} / \mathrm{ml}$ aprotinin) and quantified using the BCA protein quantification kit (cat. no. ab102536; Abcam). The cell lysates (30 $\mu \mathrm{g}$ protein/lane) were separated by $8 \%$ SDS-PAGE, the samples (30 $\mu \mathrm{g}$ protein/lane) were transferred to a nitrocellulose membrane (Immoblin-P, Millipore; Merck KGaA). After blocking with 5\% skim milk in tris-buffered saline Tween-20 (TBST) buffer (10 mM Tris-HCl pH 7.4, $150 \mathrm{mM}$ $\mathrm{NaCl}, 0.1 \%$ Tween-20) at room temperature for $1 \mathrm{~h}$, antibodies against MET, p-MET, SRC, p-SRC, AKT, p-AKT, EGFR, p-EGFR, IGF-1R, p-IGF-1R, PARP, $\beta$-actin, anti-ERK and p-ERK1/ERK2 were added and incubated overnight at $4^{\circ} \mathrm{C}$. Following three washes with TBST buffer, the membrane was incubated with secondary goat anti-rabbit and goat anti-mouse antibodies for $30 \mathrm{~min}$ at room temperature followed by three washes with TBST buffer. Finally, the protein bands were detected with enhanced chemiluminescence reagent (SuperSignal $^{\mathrm{TM}}$ Western Pico Chemiluminescent Substrate; Pierce; Thermo Fisher Scientific, Inc.) and scanned using the Electrophoresis Gel Imaging Analysis System (DNR Bio-Imaging Systems, Neve Yamin, Israel).

Small interfering RNA (siRNA) transfections. The MET and SRC siRNA (5 nM) sequences from Shanghai GenePharma 
Co., Ltd. (Shanghai, China) were as follows: 5'-GCCUGA AUGAUGACAUUCU-3' and 5'-GGCUCCAGAUUGUCA ACAAtt-3', respectively. Furthermore, the siRNA were transfected with Lipofectamine ${ }^{\circledR} 2000$ (Invitrogen; Thermo Fisher Scientific, Inc.), according to the manufacturer's instructions (Invitrogen; Thermo Fisher Scientific, Inc.). EGF or IGF-1 were added to the cells for $2 \mathrm{~h}$ at $37^{\circ} \mathrm{C}, 48 \mathrm{~h}$ after transfection and collected for further study.

Plasmid construction. Flag-tagged wild type SRC plasmid was kindly provided by Dr. Li Feng (Department of Cell Biology, China Medical University, Shenyang, China). pcDNA3.1 was purchased from Invitrogen (Thermo Fisher Scientific, Inc.) and used as a negative control. Furthermore, cells were transfected with $2 \mu$ g plasmid or empty control using Lipofectamine ${ }^{\circledR} 2000$, according to the manufacturer's instructions.

Co-immunoprecipitation. HCT-116 cells $\left(8 \times 10^{6}\right)$ were seeded into $100 \mathrm{~mm}$ plates and allowed to attach overnight at $37^{\circ} \mathrm{C}$. The cells were then washed twice with PBS and lysed in lysis buffer on ice. Co-immunoprecipitation was performed using $200 \mu \mathrm{g}$ lysates with $4 \mu \mathrm{l}$ of mouse anti-MET or control immunoglobulin $G$ mixed with protein $G$ agarose beads (GE Healthcare Bio-Sciences, Pittsburgh, PA, USA). The final mixture was gently rocked overnight at $4^{\circ} \mathrm{C}$. Following this, the beads were spun down for $1 \mathrm{~min}$ at $13,000 \mathrm{x} \mathrm{g}$ at $4^{\circ} \mathrm{C}$ and washed four times for $1 \mathrm{~min}$ with lysis buffer $(1 \%$ Triton X-100, $50 \mathrm{mM}$ Tris- $\mathrm{HCl} \mathrm{pH}$ 7.4, $150 \mathrm{mM} \mathrm{NaCl}, 10 \mathrm{mM}$ EDTA, $100 \mathrm{mM} \mathrm{NaF}, 1 \mathrm{mM} \mathrm{Na}_{3} \mathrm{VO}_{4}, 1 \mathrm{mM}$ PMSF and $2 \mu \mathrm{g} / \mathrm{ml}$ aprotinin). Finally, $40 \mu \mathrm{l}$ sampling buffer (Beyotime Institute of Biotechnology, Haimen, China) was added, boiled at $95^{\circ} \mathrm{C}$ for $5 \mathrm{~min}$ and subjected to western blot analysis.

Colony formation assay. Cells were seeded at 300 cells/well in 12 -well plates. Following culture for $24 \mathrm{~h}$ at $37^{\circ} \mathrm{C}$ in RPMI-1640 medium supplemented with $10 \%$ FBS, cells were treated with either $0.2 \mu \mathrm{M}$ PHA-665752, $50 \mathrm{nM}$ dasatinib or a combination (0.2 $\mu$ M PHA-665752 and $50 \mathrm{nM}$ dasatinib). The cells were then cultured for an additional 10 days at $37^{\circ} \mathrm{C}$, then stained with Wright Giemsa, after which the number of colonies was counted using a fluorescence microscope (BX53; Olympus Corporation, Tokyo, Japan).

Flow cytometry assay. The cells were collected and washed twice for 5 min with PBS. Following blocking in 70\% ethanol at $4^{\circ} \mathrm{C}$ for $12 \mathrm{~h}$, the samples were washed twice for $5 \mathrm{~min}$ with PBS and incubated with $20 \mu \mathrm{g} / \mathrm{ml}$ RNase A (R4642; Sigma-Aldrich; Merck KGaA) for $30 \mathrm{~min}$ at $37^{\circ} \mathrm{C}$ and $10 \mu \mathrm{g} / \mathrm{ml}$ propidium iodide for $30 \mathrm{~min}$ at room temperature in the dark. Finally, the samples were evaluated by flow cytometry (BD Accuri C6; BD Biosciences, San Jose, CA, USA), and analyzed with WinMDI version 2.9 software (The Scripps Research Institute, La Jolla, CA, USA).

Statistical analysis. Data were analyzed using SPSS version 21.0 software (SPSS Corp., Chicago, IL, USA). All the values were expressed as the mean \pm standard deviation. Furthermore, the differences of the results between the two groups were determined by Student's t-tests. $\mathrm{P}<0.05$ was considered to indicate a statistically significant difference.

\section{Results}

Ligand-dependent activation of MET in colon cancer cells. First, to ensure the HGF/MET axis was functional in wild type and mutant RAS colon cancer cells, HT-29 (wild type RAS) and HCT-116 (mutant RAS) cells were added to different doses of HGF for $48 \mathrm{~h}$. MTT assays revealed a significant increase in HGF cell viability in colon cancer cells of 7.6-17.4\% $(\mathrm{P}<0.05$ vs. $0 \mathrm{ng} / \mathrm{ml} \mathrm{HGF}$; Fig. 1A). Notably, it was observed that the increase of cell viability induced by HGF was not in a dose-dependent manner. The highest dose of HGF $(125 \mathrm{ng} / \mathrm{ml})$ demonstrated a smaller increase in cell viability than the $25 \mathrm{ng} / \mathrm{ml}$ HGF dose. Therefore, $25 \mathrm{ng} / \mathrm{ml}$ HGF was selected to study the effect on cell viability. Subsequently, the expression of MET phosphorylation and successive downstream cascades was evaluated by western blotting. As expected, robust activation of MET on Tyr 1234/1235 was observed to peak at 15 min after HGF addition in both cell lines, and decreased gradually after this. Phosphorylation of SRC, AKT and ERK was elevated following the addition of HGF and this was accompanied by MET activation (Fig. 1B and C). These results indicated that a ligand-dependent activation of MET by HGF promoted cell viability in colon cancer cells.

Ligand-independent activation of MET by EGF and IGF-1. Apart from ligand activation by HGF, MET may be activated in the absence of ligand binding by crosstalk with other growth factor receptors $(9,10)$. To further demonstrate the ligand-independent activation of MET in wild type and mutant RAS colon cancer cells, $25 \mathrm{ng} / \mathrm{ml}$ EGF or IGF-1 was added to HT-29 and HCT-116 cells at $15 \mathrm{~min}$ and 2, 8 and $16 \mathrm{~h}$. In contrast to acute activation of EGFR and IGF-1R signaling and downstream cascades (including SRC, AKT and ERK) after EGF and IGF-1 addition, MET phosphorylation appeared to be activated later, at $2 \mathrm{~h}$ after the addition of EGF or IGF-1 (Fig. 2A-D). Furthermore, no differences in MET expression were evident by western blotting. To demonstrate the role of MET on ligand-independent activation, the expression of MET was inhibited by siRNA before the addition of EGF or IGF-1. As expected, the ligand-independent activation of MET stimulated by EGF or IGF-1 was evidently attenuated (Fig. 2E and F). These results demonstrated that the MET pathway cross talked with the EGFR and IGF-1R pathways in colon cancer cells.

MET inhibition exhibits a limited anti-viability effect in colon cancer cells. Since the HGF/MET pathway contributed to increased cellular viability, including cross talk with other growth factor receptor pathways, the present study aimed to assess the anti-viability activity of MET inhibition in colon cancer cells. Knockdown of MET by siRNA led to significant inhibition of cell viability in HT-29 (77.8 \pm 6.18 vs. $100 \%$; $\mathrm{P}=0.012)$ and HCT-116 (82.9 $\pm 4.45 \%$ vs. $100 \% ; \mathrm{P}=0.011$; Fig. 3A) cells compared with scramble controls. Furthermore, a selective MET inhibitor, PHA-665752, was used; however, this induced no significant inhibition to cell viability (Fig. 3B). The anti-viability activity of PHA-665752 was dose-dependent, with the highest dose of PHA-665752 $(5 \mu \mathrm{M})$ having inhibitory rates of 34.5 and $25.5 \%$ in HT-29 and HCT-116 cells, respectively (Fig. 3B). Subsequently, the change of the signaling 

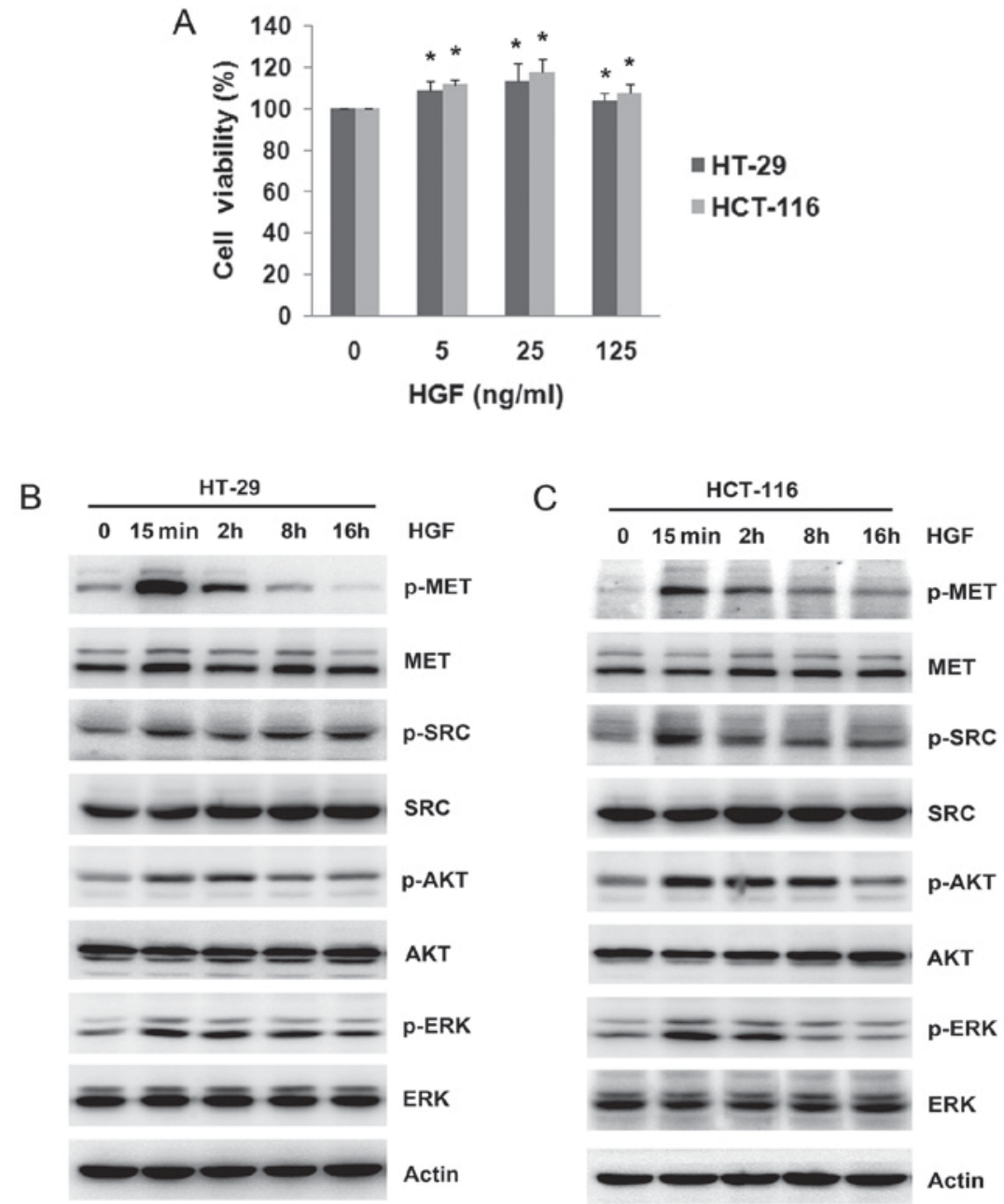

Figure 1. Effects of HGF on cell viability in colon cancer cells. (A) Various concentrations of HGF (5, 25 and $125 \mathrm{ng} / \mathrm{ml})$ were added to HT-29 and HCT-116 cells for $48 \mathrm{~h}$. Cell viability was determined by MTT assay. Data are presented as the mean \pm standard deviation of three independent experiments. HGF ( $25 \mathrm{ng} / \mathrm{ml}$ ) was added to (B) HT-29 and (C) HCT-116 cells and the expression and phosphorylation of MET, SRC, AKT and ERK was studied by western blotting. Actin was used as a loading control. "P<0.05 vs. 0 ng/ml HGF. HGF, hepatocyte growth factor; AKT, protein kinase B; ERK, extracellular signal-regulated kinase; p, phosphorylated.

pathway after the addition of PHA-665752 was examined. The single use of PHA-665752 markedly inhibited the basal level of MET phosphorylation, as predicted (Fig. 3C and D). However, the basal phosphorylation levels of SRC, AKT or ERK were not inhibited by PHA-665752 (Fig. 3C and D). Pretreatment with PHA-665752 markedly suppressed the activation and/or phosphorylation of MET, SRC, AKT or ERK stimulated by HGF (Fig. 3E). Altogether, MET inhibition led to the inhibition of cell viability in colon cancer cells.

SRC activation is essential for ligand-dependent and ligand-independent MET activation. As SRC activation was commonly accompanied by ligand-dependent and -independent activation of MET, and SRC was the key mediator downstream of the MET pathway, the interaction between MET and SRC in colon cancer cells was examined. First, a co-immunoprecipitation assay was performed, which revealed a physical interaction between MET and SRC in HCT-116 cells (Fig. 4A). Knockdown of MET by siRNA decreased SRC phosphorylation without altering its total expression (Fig. 2E and F). To explore the role of SRC on MET activity,
siRNA was used to knockdown SRC expression and wild type SRC plasmid was used to enhance SRC expression. Similarly, SRC knockdown resulted in a decrease of MET phosphorylation (Fig. 4B); while overexpression of SRC with a plasmid harboring an activated wild type SRC was sufficient to directly phosphorylate MET without altering its total expression (Fig. 4C). Furthermore, the addition of the multitargeted SFK inhibitor, dasatinib, at different concentrations inhibited the basal level of MET phosphorylation, accompanied by decreased phosphorylation of AKT and ERK in HT-29 and HCT-116 cells (Fig. 4D and E). These results suggested that MET may be a direct target of SRC in colon cancer cells.

To examine the potential role of SRC activity in delayed MET activation, pretreatment with dasatinib was used before stimulating cells with HGF, EGF or IGF-1, respectively. Under these conditions, pretreatment with dasatinib reduced growth factor-induced MET activation and led to a partial decrease in the phosphorylation of AKT and ERK in HT-29 cells compared with growth factor stimulation (Fig. 4F-H). These results suggested that SRC activation was required for ligand-dependent and ligand-independent MET activation. 

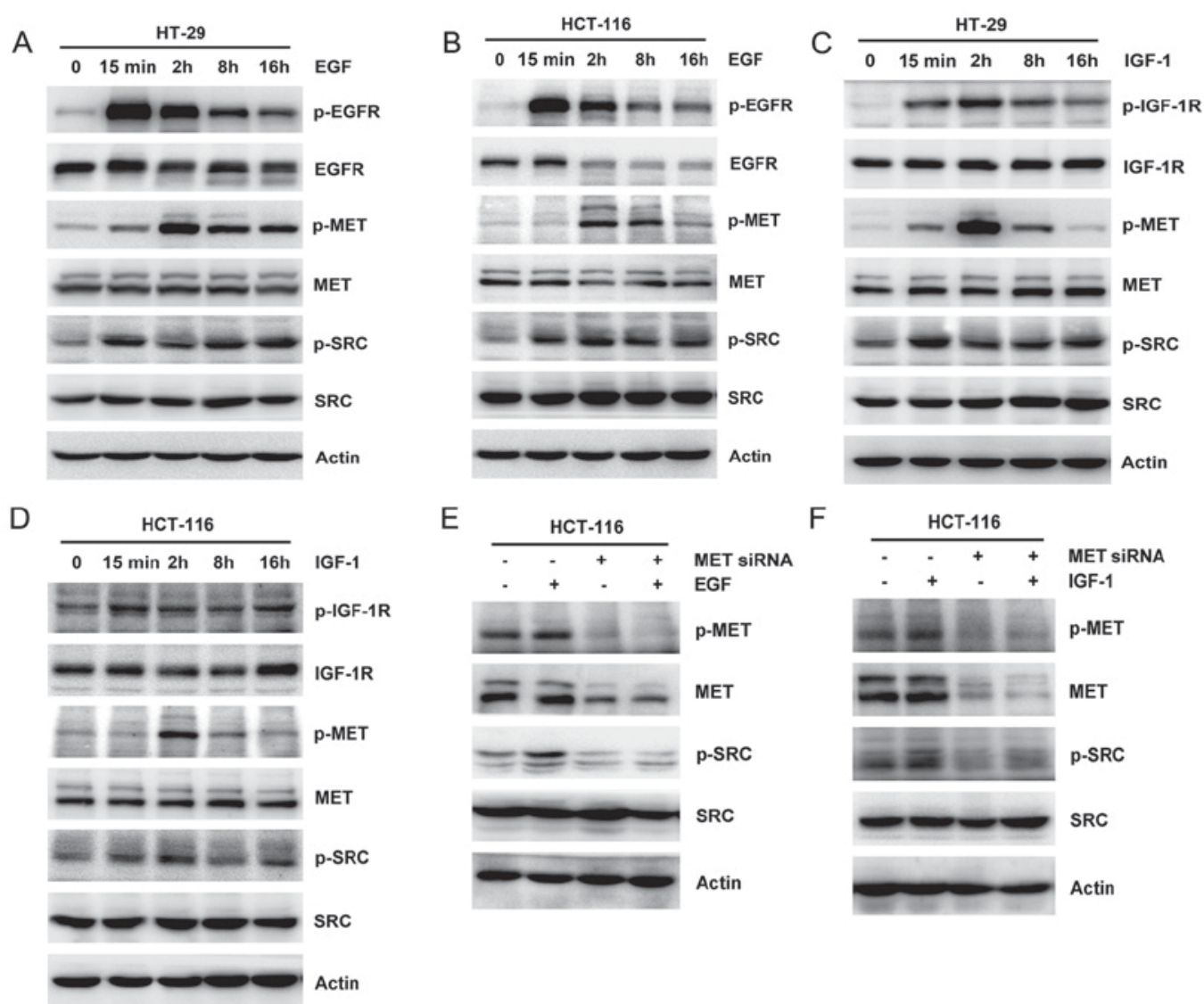

Figure 2. Effect of EGF and IGF-1 on MET activation. EGF (25 ng/ml) was added to (A) HT-29 and (B) HCT-116 cells and the expression and phosphorylation of EGFR, MET, SRC, AKT and ERK was assessed by western blotting. IGF-1 (25 ng/ml) was added to (C) HT-29 and (D) HCT-116 cells. The expression and phosphorylation of IGF-1R, MET, SRC, AKT and ERK were observed by western blotting. HCT-116 cells were transiently transfected with scramble control or MET siRNA, and then $25 \mathrm{ng} / \mathrm{ml}$ (E) EGF or (F) IGF-1 was added for $2 \mathrm{~h}$. The expression and phosphorylation of MET and SRC were studied by western blotting. Actin was used as a loading control. EGF, epidermal growth factor; EGFR, epidermal growth factor receptor; AKT, protein kinase B; ERK, extracellular signal-regulated kinase; IGF-1, insulin-like growth factor-1; IGF-1R, insulin-like growth factor-1 receptor; siRNA, small interfering RNA; p, phosphorylated .

Combinational inhibition of MET and SRC exerts increased antitumor effects. Although dasatinib partly repressed the growth factor-induced activation of MET, AKT and ERK, the inhibitory effect was not complete. Therefore, the present study focused on the mechanisms of dual inhibition of MET and SRC. Initially, the concurrent inhibition of MET and SRC was observed in ligand-dependent and -independent MET activation. As expected, pretreatment with MET and SRC inhibitors markedly inhibited the activation of MET and SRC stimulated by growth factors compared to single inhibition in HCT-116 cells (Fig. 5). Following this, the effect of combined treatment with MET and SRC inhibitors was evaluated. Combination treatment resulted in a significant decrease in cell viability compared with single agent treatment in HT-29 cells $(56.5 \pm 5.2 \%$ in combination treatment vs. $85.9 \pm 4.4 \%$ in PHA-665752 treatment; $\mathrm{P}=0.001$; and $56.5 \pm 5.2 \%$ in combination treatment vs. $66.9 \pm 5.4 \%$ in dasatinib treatment; $\mathrm{P}=0.008)$ and in HCT-116 cells $(63.7 \pm 7.6 \%$ in combination treatment vs. $86.8 \pm 3.8 \%$ in $\mathrm{PHA}-665752$ treatment; $\mathrm{P}=0.006$; and $63.7 \pm 7.6 \%$ in combination treatment vs. $74.3 \pm 3.9 \%$ in dasatinib treatment; $\mathrm{P}=0.033$; Fig. 6A). Similarly, colonies that formed in the presence of the combined treatment were markedly smaller and fewer in number than those that grew with either of the single agent treatments (Fig. 6B). These results demonstrated that the combination of MET with SRC inhibitor enhanced the anti-viability effects of these treatments alone.

Western blotting revealed that combined treatment with PHA-665752 and dasatinib further decreased phosphorylation of MET, SRC, AKT and ERK in HT-29 and HCT-116 cells (Fig. 6C). Additionally, it was revealed that a combination of PHA-665752 and dasatinib significantly enhanced apoptosis in HT-29 cells, as detected by PARP cleavage and the increased the proportion of apoptotic cells $(\mathrm{P}<0.05$; Fig. $6 \mathrm{D}$ and $\mathrm{E})$. The proportion of apoptotic cells was $40.6 \pm 6.9 \%$ in the combination treatment group, which was significantly more than the proportion of apoptotic cells after single PHA-665752 $(14.8 \pm 4.2 \% ; \mathrm{P}=0.003)$ or dasatinib $(22.6 \pm 4.1 \% ; \mathrm{P}=0.004)$ treatment in HT-29 cells. These results demonstrated that dual inhibition of MET and SRC exerted superior proliferation inhibition and apoptosis enhancement than either agent alone.

\section{Discussion}

In targeted therapy, numerous studies have suggested that combining inhibition of tyrosine kinases may be a beneficial therapeutic strategy $(3,23)$. To date, few therapeutic targeting options are available, particularly in patients with CRC with mutated RAS. In the present study, the important role of MET activation in ligand-dependent activation by HGF and 
A

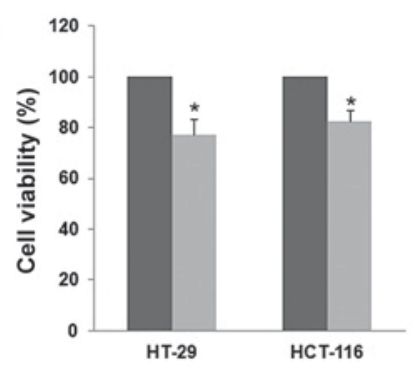

C

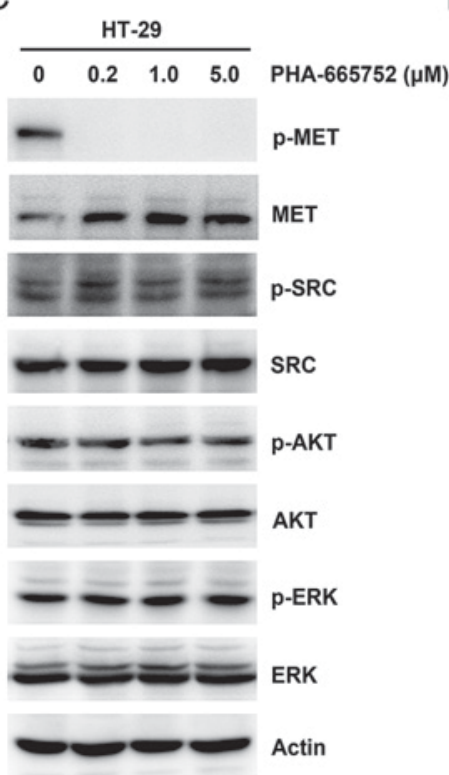

$=$ MET SIRNA

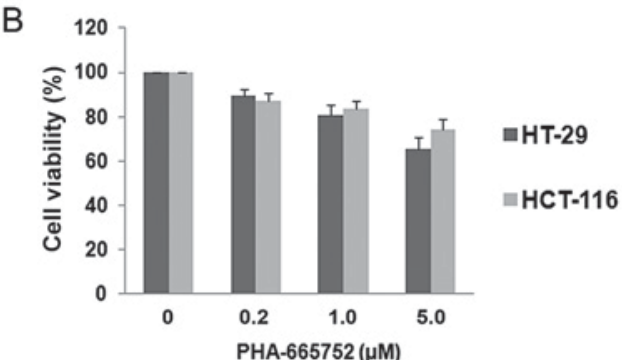

D

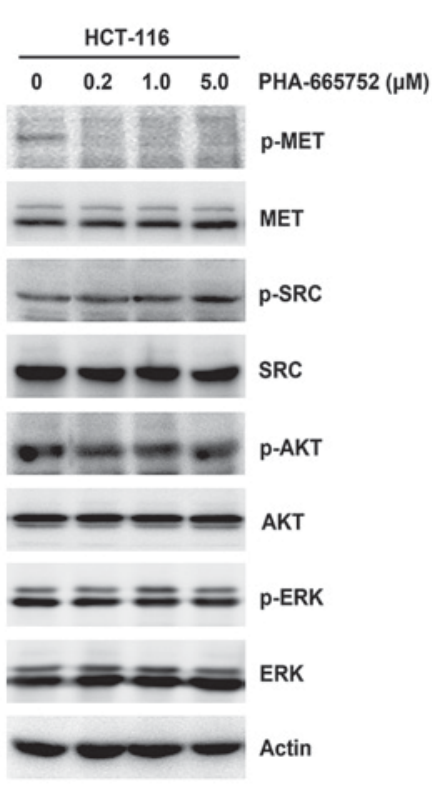

$\mathrm{E}$

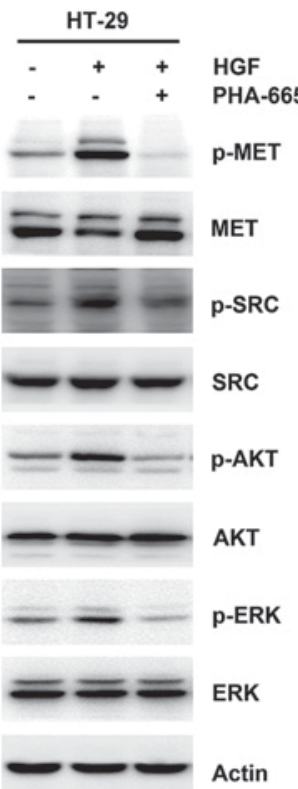

Figure 3. MET inhibition by siRNA or inhibitor. (A) HT-29 and HCT-116 cells were transiently transfected with scramble control or MET siRNA for $48 \mathrm{~h}$ in 96-well plates. Cell viability was assessed by MTT assay. (B) Increasing concentrations of PHA-665752 (0.2, 1.0 and $5.0 \mu \mathrm{M})$ were added to HT-29 and HCT-116 cells, and cell viability was assessed after $48 \mathrm{~h}$. Data are presented as the mean \pm standard deviation of three independent experiments. Increasing concentrations of PHA-665752 (0.2, 1.0 and $5.0 \mu \mathrm{M})$ were added to (C) HT-29 and (D) HCT-116 cells for $24 \mathrm{~h}$. The expression and phosphorylation of MET, SRC, AKT and ERK were studied by western blotting. (E) HCT-116 cells were pretreated with $0.2 \mu \mathrm{M}$ PHA-665752 for $24 \mathrm{~h}$ after which they were stimulated with $25 \mathrm{ng} / \mathrm{ml} \mathrm{HGF}$ for $2 \mathrm{~h}$. The expression and phosphorylation of MET, SRC, AKT and ERK were analyzed by western blotting. Actin was used as a loading control. "P<0.05 vs. scramble control. siRNA, small interfering RNA; AKT, protein kinase B; ERK, extracellular signal-regulated kinase; p, phosphorylated.

ligand-independent activation by EGF and IGF-1 was investigated in colon cancer cells. It was demonstrated that SRC was the key factor that mediated the interaction of MET with EGFR or IGF-1R. Therefore, combined treatment with MET and SRC inhibitors exhibited increased inhibition of cell viability and apoptosis, which provided novel insights into dual targeting of MET and SRC in colon cancer cells.

$\mathrm{HGF} / \mathrm{MET}$ signaling is essential in aberrant processes of cell survival, growth, angiogenesis and metastasis (24). Aberrant MET activation may mediate resistance to targeted therapies, and ultimately result in treatment failure $(22,25)$. The results of the present study demonstrated that HGF promoted cell viability to a greater extent at a lower concentration of $25 \mathrm{ng} / \mathrm{ml}$ compared to a higher concentration of $125 \mathrm{ng} / \mathrm{ml}$, while colon cancer cells may predominantly exhibit manifestation of epithelial-to-mesenchymal transition in a higher concentration of HGF (26). In addition, MET signaling was involved in an intricate network of cross-signaling through multiple ligand-independent mechanisms. The results of the present study demonstrated that the main growth factors, including EGF and IGF-1, induced delayed MET activation in colon cancer cells. HGF/MET signaling is essential for the maintenance of colon cancer stem cells (27). Therefore, targeting MET signaling may be an important therapeutic strategy in CRC.

Recent studies have clearly indicated that targeting HGF/MET may have potential activity in several groups of cancer patients either alone or with inhibitors of other signaling pathways $(28,29)$. In colon cancer cells, inhibition of MET by siRNA or inhibitors demonstrated certain anti-viability effects, with $\sim 20 \%$ cell viability inhibition. However, the MET inhibitor, PHA-665752, failed to inhibit autophosphorylation of SRC, AKT and ERK in HT-29 and HCT-116 cells, while PHA-665752 effectively abrogated activation of SRC, AKT and ERK stimulated by HGF. Thus, the sustained activation of downstream MET signaling may cause limited anti-viability effects for the MET inhibitor in colon cancer.

SRC has been demonstrated to be a key downstream transducer of MET-driven tumor growth (30) and the activity of SRC is important for the growth of CRC cells (31). The results of the present study demonstrated that there was a mutually strong interaction between MET and SRC in colon 

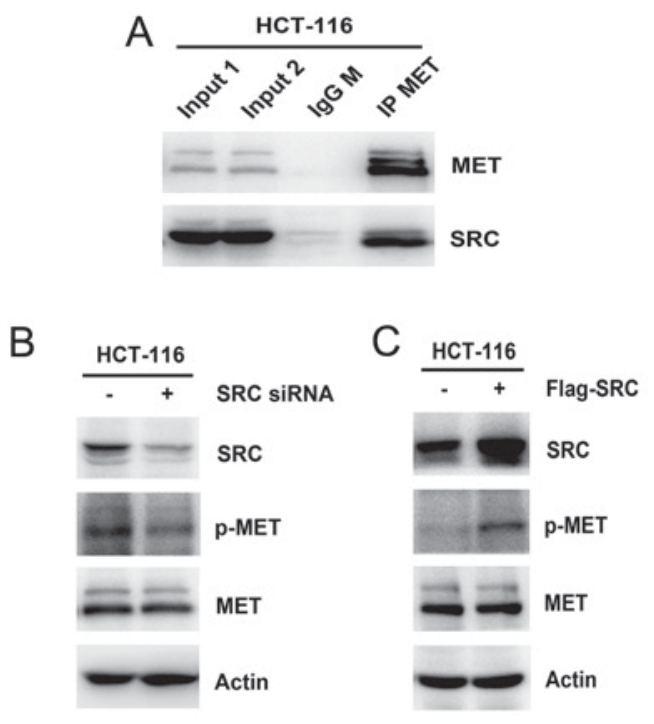

$\mathrm{F}$

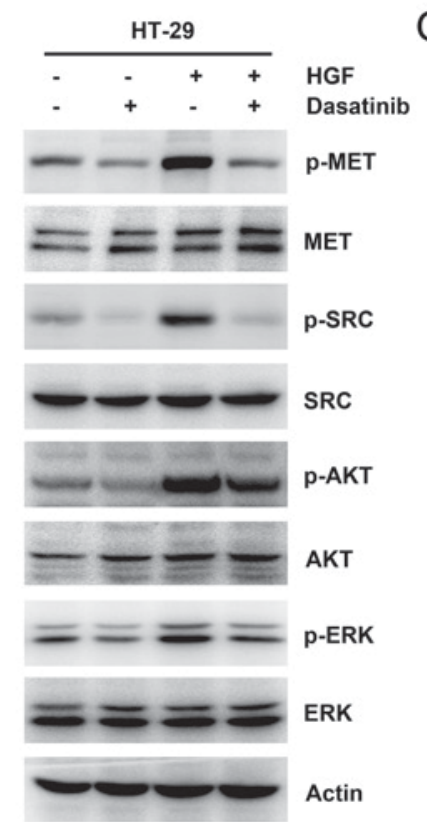

D

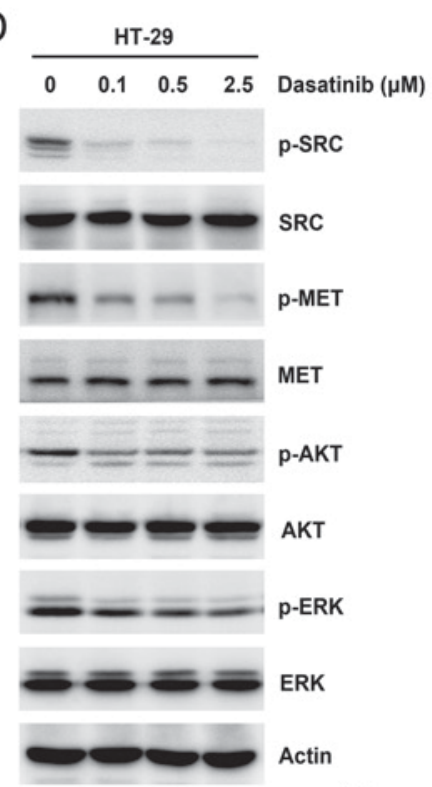

$\mathrm{E}$
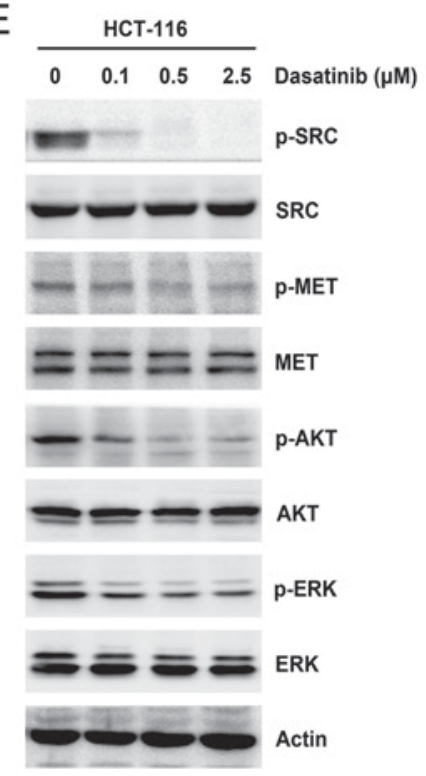

$\mathrm{H}$
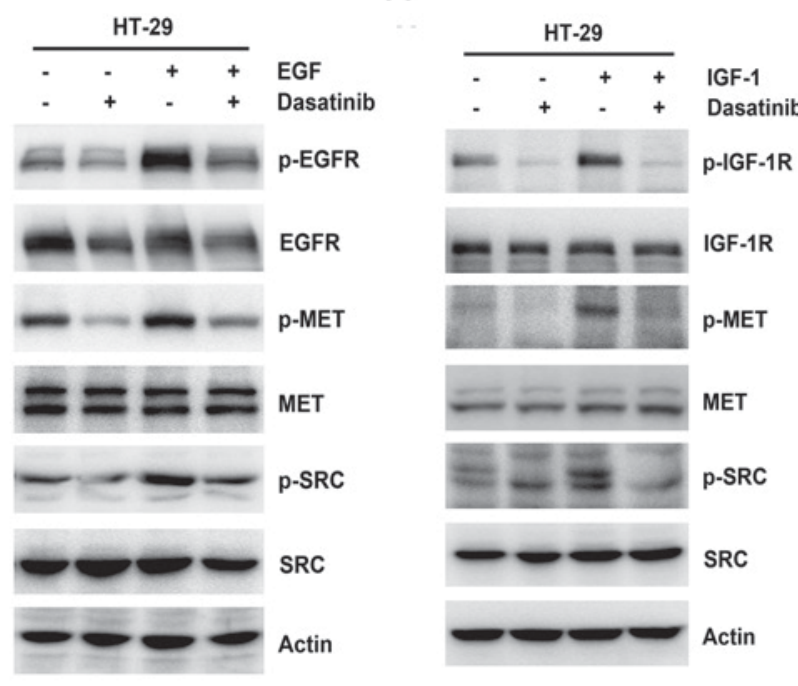

Figure 4. Regulation of SRC on MET and non-ligand mediated MET activation. (A) Whole-cell extracts from HCT-116 cells were immunoprecipitated with anti-MET antibody. The immunoprecipitates were probed with MET and SRC antibodies. The input represents cell lysates that were not subjected to immunoprecipitation. Control immunoprecipitation was performed using IgG M. HCT-116 cells were transiently transfected with scramble control and (B) SRC siRNA for $48 \mathrm{~h}$ or (C) flag-tagged wild type SRC plasmid for $24 \mathrm{~h}$. The expression of SRC, MET and p-MET was studied by western blotting. Increasing concentrations of dasatinib $(0.1,0.5$ and $2.5 \mu \mathrm{M})$ were added to (D) HT-29 and (E) HCT-116 cells, and the expression and phosphorylation of SRC, MET, AKT and ERK was analyzed by western blotting. (F) HT-29 cells were pretreated with $0.1 \mu \mathrm{M}$ dasatinib for $24 \mathrm{~h}$, then stimulated with $25 \mathrm{ng} / \mathrm{ml} \mathrm{HGF}$ for $2 \mathrm{~h}$. The expression and phosphorylation of MET, SRC, AKT and ERK was examined by western blotting. HT- 29 cells were pretreated with $0.1 \mu \mathrm{M}$ dasatinib for $24 \mathrm{~h}$, then stimulated with $25 \mathrm{ng} / \mathrm{ml}$ (G) EGF or (H) IGF-1 for $2 \mathrm{~h}$. The expression and phosphorylation of EGFR, IGF-1R, MET and SRC was studied by western blotting. Actin was used as a loading control. IgG M, immunoglobulin G mouse; siRNA, small interfering RNA; p, phosphorylated; AKT, protein kinase B; ERK, extracellular signal-regulated kinase; HGF, hepatocyte growth factor; EGF, epidermal growth factor; EGFR, epidermal growth factor receptor; IGF-1, insulin-like growth factor-1; IGF-1R, insulin-like growth factor-1 receptor.

cancer cells. SRC effectively influenced the activation of MET through the physical complex of MET and SRC, according to the co-immunoprecipitation assay and transfection experiments with siRNA sequences or overexpression plasmids. Although the SRC inhibitor, dasatinib, reduced MET autophosphorylation and decreased MET phosphorylation by stimulating factors, the inhibition was not complete. In addition, SRC inhibitors have been demonstrated to be effective in certain solid tumors; however, sustained MET activation may mediate resistance to SRC inhibition in head and neck, and gastric cancer $(32,33)$. Additionally, in gefitinib-resistant lung cancer cells with MET amplification, SRC activation is more dependent on MET signaling (34). In these cases, combinatorial treatment using targeted SRC and MET inhibitors may exhibit synergistic cytotoxic effects.

Therefore, combinational treatment using MET and SRC inhibitors was performed in colon cancer cells. The results indicated that the mutual interaction between MET and SRC 
A

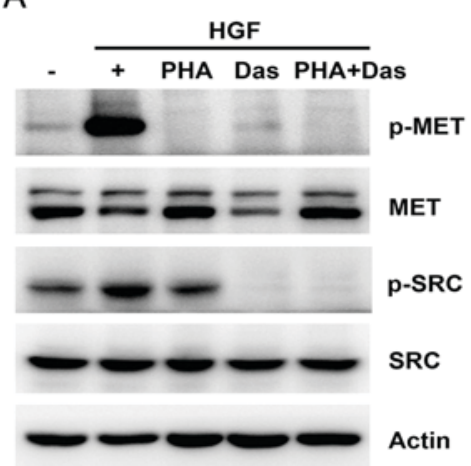

B

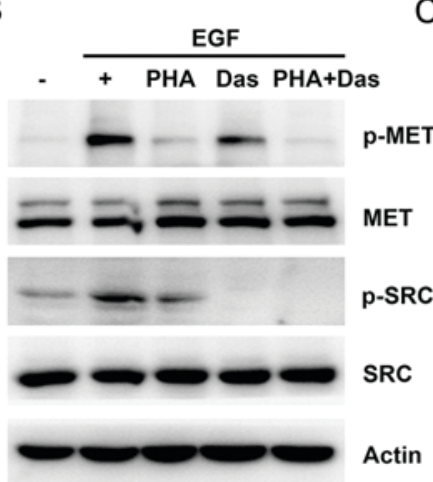

C

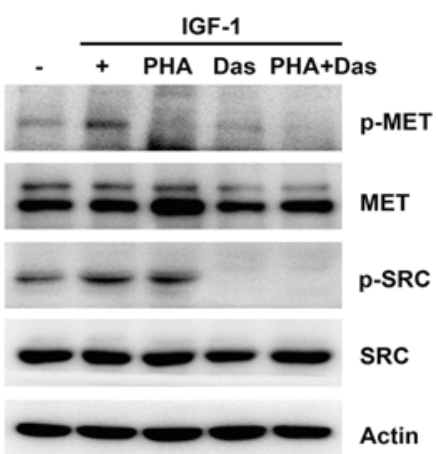

Figure 5. Effect of combining MET and SRC inhibition. HCT-116 cells were pretreated with $0.5 \mu \mathrm{M}$ Das, $0.2 \mu \mathrm{M}$ PHA or combination for $24 \mathrm{~h}$, and then $25 \mathrm{ng} / \mathrm{ml}$ (A) HGF, (B) EGF or (C) IGF-1 was added for $2 \mathrm{~h}$. The expression and phosphorylation of MET and SRC was analyzed by western blotting. Actin was used as a loading control. PHA, PHA-665752; Das, dasatinib; HGF, hepatocyte growth factor; EGF, epidermal growth factor; IGF-1, insulin-like growth factor-1; p, phosphorylated.$$
\text { A }
$$

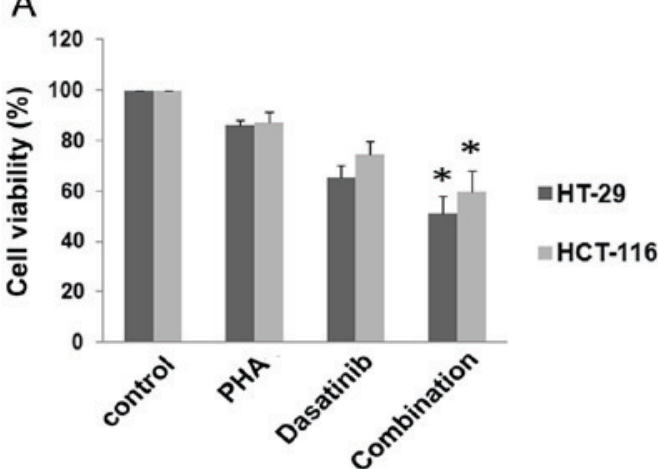

c

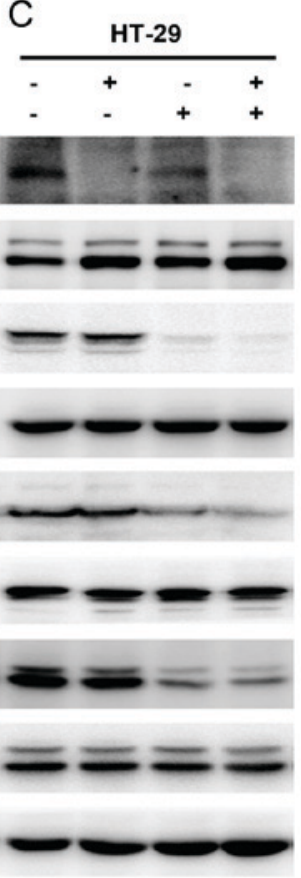

B

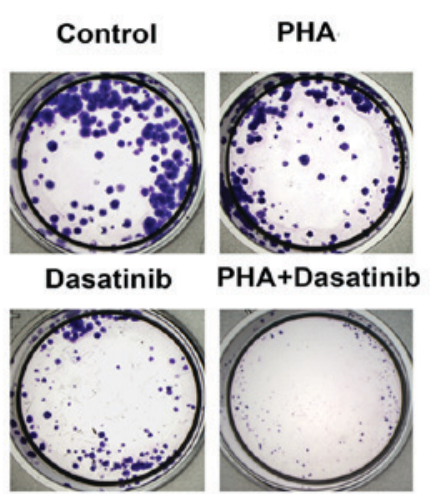

D

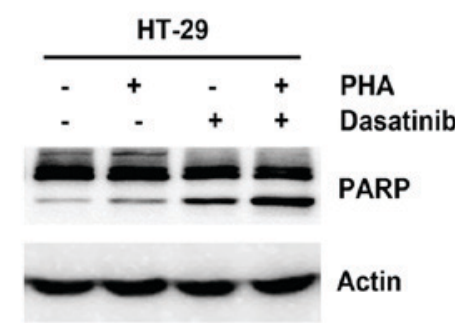

E

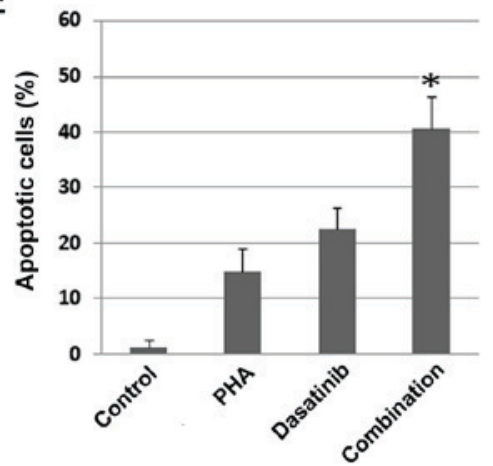

Figure 6. Effect of combining MET and SRC inhibition on cell viability. (A) HT-29 and HCT-116 cells were treated with $0.1 \mu \mathrm{M}$ dasatinib, $0.2 \mu \mathrm{M}$ PHA or combination for $48 \mathrm{~h}$, and cell viability was assessed by MTT assay. (B) HCT-116 cells were treated with $50 \mathrm{nM}$ dasatinib, $0.2 \mu \mathrm{M}$ PHA or combination for 10 days, and the clones were counted. (C) HT-29 and HCT-116 cells were treated with $0.1 \mu \mathrm{M}$ dasatinib, $0.2 \mu \mathrm{M}$ PHA or combination for $24 \mathrm{~h}$. The expression and phosphorylation of MET, SRC, AKT and ERK was analyzed by western blotting. (D) HT-29 cells were treated with $0.1 \mu \mathrm{M}$ dasatinib, $0.2 \mu \mathrm{M}$ PHA or combination for $48 \mathrm{~h}$, and the expression of PARP was detected by western blotting. (E) HT-29 cells were treated with $0.1 \mu \mathrm{M}$ dasatinib, $0.2 \mu \mathrm{M}$ PHA or combination for $48 \mathrm{~h}$. The proportion of apoptotic cells was examined by flow cytometric assay. Actin was used as a loading control for western blotting. Data are presented as the mean \pm standard deviation from three separate experiments where appropriate. "P $<0.05$ vs. PHA- 665752 alone or dasatinib alone. PHA, PHA-665752; AKT, protein kinase B; ERK, extracellular signal-regulated kinase; PARP, poly (ADP-ribose) polymerase; p, phosphorylated. 
was strongly linked in colon cancer cells. Furthermore, the combination of PHA-665752 and dasatinib inhibited cell growth by decreasing cell viability and increasing apoptosis. The combined treatment prevented ligand-dependent and ligand-independent activation of MET and SRC, and further decreased basal phosphorylation of SRC, AKT and ERK in the two cell types. These results indicated that combinatorial inhibition of MET and SRC may be essential to effectively suppress activation of the HGF/MET pathway. Furthermore, combined therapy demonstrated the same antitumor effect, particularly in RAS mutant colon cancer cells.

In conclusion, the present study demonstrated that MET and SRC are essential in ligand-dependent and ligand-independent MET activation. Thus, combined inhibition of MET and SRC may possess enhanced cytotoxicity, providing a strong basis for assessing the therapeutic value of concurrent inhibition of MET and SRC in CRC.

\section{Acknowledgements}

The present study was supported by grants from the Chinese National Foundation of National Sciences Grants (grant nos. 81401938 and 81372546), the National Science and Technology Major Project of the Ministry of Science and Technology of China (grant no. 2013JX09303002) and the Science and Technology Plan Project of Liaoning Province (grant nos. 2014225013 and 2014021089).

\section{References}

1. Cremolini C, Loupakis F, Antoniotti C, Lupi C, Sensi E, Lonardi S, Mezi S, Tomasello G, Ronzoni M, Zaniboni A, et al: FOLFOXIRI plus bevacizumab versus FOLFIRI plus bevacizumab as first-line treatment of patients with metastatic colorectal cancer: Updated overall survival and molecular subgroup analyses of the open-label, phase 3 TRIBE study. Lancet Oncol 16: 1306-1315, 2015.

2. Maurel J and Postigo A: Prognostic and predictive biomarkers in colorectal cancer. From the preclinical setting to clinical practice. Curr Cancer Drug Targets 15: 703-715, 2015.

3. Grothey A, Van Cutsem E, Sobrero A, Siena S, Falcone A, Ychou M, Humblet Y, Bouché O, Mineur L, Barone C, et al: Regorafenib monotherapy for previously treated metastatic colorectal cancer (CORRECT): An international, multicentre, randomised, placebo-controlled, phase 3 trial. Lancet 381 303-312, 2013

4. Wilhelm SM, Dumas J, Adnane L, Lynch M, Carter CA, Schütz G, Thierauch KH and Zopf D: Regorafenib (BAY 73-4506): A new oral multikinase inhibitor of angiogenic, stromal and oncogenic receptor tyrosine kinases with potent preclinical antitumor activity. Int J Cancer 129: 245-255, 2011.

5. Sartore-Bianchi A, Siena S, Tonini G, Bardelli A and Santini D: Overcoming dynamic molecular heterogeneity in metastatic colorectal cancer: Multikinase inhibition with regorafenib and the case of rechallenge with anti-EGFR. Cancer Treat Rev 51: $54-62,2016$.

6. Winder T and Lenz HJ: Vascular endothelial growth factor and epidermal growth factor signaling pathways as therapeutic targets for colorectal cancer. Gastroenterology 138: 2163-2176, 2010.

7. Gherardi E, Birchmeier W, Birchmeier C and Vande Woude G: Targeting MET in cancer: Rationale and progress. Nat Rev Cancer 12: 89-103, 2012.

8. Mitra AK, Sawada K, Tiwari P, Mui K, Gwin K and Lengyel E: Ligand-independent activation of c-Met by fibronectin and $\alpha(5) \beta(1)$-integrin regulates ovarian cancer invasion and metastasis. Oncogene 30: 1566-1576, 2011.

9. Dulak AM, Gubish CT, Stabile LP, Henry C and Siegfried JM: HGF-independent potentiation of EGFR action by c-Met. Oncogene 30: 3625-3635, 2011.
10. Varkaris A, Gaur S, Parikh NU, Song JH, Dayyani F, Jin JK, Logothetis CJ and Gallick GE: Ligand-independent activation of MET through IGF-1/IGF-1R signaling. Int J Cancer 133: 1536-1546, 2013

11. Lee J,Jain A,Kim P, Lee T, Kuller A, Princen F, In-GuDo, Kim SH, Park JO, Park YS, et al: Activated cMET and IGF1R-driven PI3K signaling predicts poor survival in colorectal cancers independent of KRAS mutational status. PLoS One 9: e103551, 2014.

12. Peng Z, Zhu Y, Wang Q, Gao J, Li Y, Li Y, Ge S and Shen L: Prognostic significance of MET amplification and expression in gastric cancer: A systematic review with meta-analysis. PLoS One 9: e84502, 2014.

13. Guo B, Cen H, Tan X, Liu W and Ke Q: Prognostic value of MET gene copy number and protein expression in patients with surgically resected non-small cell lung cancer: A meta-analysis of published literatures. PLoS One 9: e99399, 2014.

14. Bardelli A, Corso S, Bertotti A, Hobor S, Valtorta E, Siravegna G, Sartore-Bianchi A, Scala E, Cassingena A, Zecchin D, et al: Amplification of the MET receptor drives resistance to anti-EGFR therapies in colorectal cancer. Cancer Discov 3: 658-673, 2013.

15. Kim LC, Song L and Haura EB: Src kinases as therapeutic targets for cancer. Nav Rev Clin Oncol 6: 587-595, 2009.

16. Stabile LP, He G, Lui VW, Thomas S, Henry C, Gubish CT, Joyce S, Quesnelle KM, Siegfried JM and Grandis JR: c-Src activation mediates erlotinib resistance in head and neck cancer by stimulating c-Met. Clin Cancer Res 19: 380-392, 2013.

17. Zhang S, Huang WC, Li P, Guo H, Poh SB, Brady SW, Xiong Y, Tseng LM, Li SH, Ding Z, et al: Combating trastuzumab resistance by targeting SRC, a common node downstream of multiple resistance pathways. Nat Med 17: 461-469, 2011.

18. Lieu C and Kopetz S: The SRC family of protein tyrosine kinases: A new and promising target for colorectal cancer therapy. Clin Colorectal Cancer 9: 89-94, 2010.

19. Vergani E, Vallacchi V, Frigerio S, Deho P, Mondellini P, Perego P, Cassinelli G, Lanzi C, Testi MA, Rivoltini L, et al: Identification of MET and SRC activation in melanoma cell lines showing primary resistance to PLX4032. Neoplasia 13: 1132-1142, 2011.

20. Mueller KL, Hunter LA, Ethier SP and Boemer JL: Met and c-Src cooperate to compensate for loss of epidermal growth factor receptor kinase activity in breast cancer cells. Cancer Res 68: 3314-3322, 2008.

21. Booth L, Roberts JL, Tavallai M, Webb T, Leon D, Chen J, McGuire WP, Poklepovic A and Dent P: The afatinib resistance of in vivo generated H1975 lung cancer cell clones is mediated by SRC/ERBB3/c-KIT/c-MET compensatory survival signaling. Oncotarget 7: 19620-19630, 2016.

22. Song N, Liu S, Zhang J, Liu J, Xu L, Liu Y and Qu X: Cetuximab-induced MET activation acts as a novel resistance mechanism in colon cancer cells. Int J Mol Sci 15: 5838-5851, 2014.

23. Llovet JM, Villanueva A, Lachenmayer A and Finn RS: Advances in targeted therapies for hepatocellular carcinoma in the genomic era. Nat Rev Clin Oncol 12: 408-424, 2015.

24. Corso S and Giordano S: Cell-autonomous and non-cell-autonomous mechanisms of HGF/MET-driven resistance to targeted therapies: From basic research to a clinical perspective. Cancer Discov 3: 978-992, 2013.

25. Liska D, Chen CT, Bachleitner-Hofmann T, Christensen JG and Weiser MR: HGF rescues colorectal cancer cells from EGFR inhibition via MET activation. Clin Cancer Res 17: 472-482, 2011.

26. Chen QY, Jiao DM, Wu YQ, Chen J, Wang J, Tang XL, Mou H, $\mathrm{Hu} \mathrm{HZ}$, Song J, Yan J, et al: MiR-206 inhibits HGF-induced epithelial-mesenchymal transition and angiogenesis in non-small cell lung cancer via c-Met /PI3k/Akt/mTOR pathway. Oncotarget 7: 18247-18261, 2016

27. Luraghi P, Reato G, Cipriano E, Sassi F, Orzan F, Bigatto V, De Bacco F, Menietti E, Han M, Rideout WM III, et al: MET signaling in colon cancer stem-like cells blunts the therapeutic response to EGFR inhibitors. Cancer Res 74: 1857-1869, 2014.

28. Smith MR, Sweeney CJ, Corn PG, Rathkopf DE, Smith DC, Hussain M, George DJ, Higano CS, Harzstark AL, Sartor AO, et al: Cabozantinib in chemotherapy-pretreated metastatic castration-resistant prostate cancer: Results of a phase II nonrandomized expansion study. J Clin Oncol 32: 3391-3399, 2014.

29. Scagliotti G, von Pawel J, Novello S, Ramlau R, Favaretto A, Barlesi F, Akerley W, Orlov S, Santoro A, Spigel D, et al: Phase III multinational, randomized, double-blind, placebo-controlled study of tivantinib (ARQ 197) plus erlotinib versus erlotinib alone in previously treated patients with locally advanced or metastatic nonsquamous non-small-cell lung cancer. J Clin Oncol 33: 2667-2674, 2015. 
30. Bertotti A, Bracco C, Girolami F, Torti D, Gastaldi S, Galimi F, Medico E, Elvin P, Comoglio PM and Trusolino L: Inhibition of Src impairs the growth of met-addicted gastric tumors. Clin Cancer Res 16: 3933-3943, 2010.

31. Emaduddin M, Bicknell DC, Bodmer WF and Feller SM: Cell growth, global phosphotyrosine elevation, and c-Met phosphorylation through Src family kinases in colorectal cancer cells. Proc Natl Acad Sci USA 105: 2358-2362, 2008.

32. Sen B, Peng S, Saigal B, Williams MD and Johnson FM: Distinct interactions between c-Src and c-Met in mediating resistance to c-Src inhibition in head and neck cancer. Clin Cancer Res 17: 514-524, 2011.
33. Okamoto W, Okamoto I, Yoshida T, Okamoto K, Takezawa K, Hatashita E, Yamada Y, Kuwata K, Arao T, Yanagihara K, et al: Identification of c-Src as a potential therapeutic target for gastric cancer and of MET activation as a cause of resistance to c-Src inhibition. Mol Cancer Ther 9: 1188-1197, 2010.

34. Yoshida T, Okamoto I, Okamoto W, Hatashita E, Yamada Y, Kuwata K, Nishio K, Fukuoka M, Jänne PA and Nakagawa K: Effects of Src inhibitors on cell growth and epidermal growth factor receptor and MET signaling in gefitinib-resistant non-small cell lung cancer cells with acquired MET amplification. Cancer Sci 101: 167-172, 2010. 